\title{
Mechanism of Oxidation of L-Histidine by Heptavalent Manganese in Alkaline Medium
}

\author{
TIMY P. JOSE ${ }^{\mathrm{a}}$, SHARANAPPA T. NANDIBEWOOR ${ }^{\mathrm{b}}$ AND SURESH M. TUWAR ${ }^{\mathrm{a} *}$ \\ ${ }^{a}$ Department of Chemistry, Karnatak Science College, Dharwad-580001, India \\ ${ }^{\mathrm{b}}$ Postgraduate Department of Studies in Chemistry, \\ Karnatak University, Dharwad-580003, India
}

Received 6 November 2004; Accepted 14 December 2004

\begin{abstract}
The kinetics of oxidation of L-histidine by manganese(VII) in aqueous alkaline medium at a constant ionic strength of $0.05 \mathrm{~mol} \mathrm{dm}^{-3}$ was studied spectrophotometrically. The reaction between permanganate and L-histidine in alkaline medium exhibits 2:1 stoichiometry $\left(\mathrm{KMnO}_{4}\right.$ : L-histidine). The reaction is of first order in $\left[\mathrm{KMnO}_{4}\right]$, less than unit order in [L-histidine] and [alkali]. Decrease in the dielectric constant of the medium decreases the rate of reaction. Effect of added products and ionic strength of the reaction medium have been investigated. The main products were identified by spot test and I.R. A mechanism involving the free radical has been proposed. In composite equilibrium step L-histidine binds to $\mathrm{MnO}_{4}{ }^{-}$species to form a complex $(C)$. The reaction constants involved in the different steps of mechanism are evaluated. The activation parameters with respect to slow step of the mechanism are computed and discussed and thermodynamic quantities are also determined.
\end{abstract}

Key words: kinetics, mechanism, oxidation, permanganate, L-histidine

\section{Introduction}

Oxidations by permanganate ion find extensive applications in organic syntheses ${ }^{1-7}$ especially since the advent of phase transfer catalysis ${ }^{3,4,6}$, which permits the use of solvents like methylene chloride and benzene. Kinetic studies are important sources of mechanistic information on these reactions, as demonstrated by result referring to unsaturated acids in both aqueous ${ }^{1-8}$ and non-aqueous media ${ }^{8}$.

As is known, in aqueous alkaline medium the permanganate ion oxidizes a number of organic compounds, which are not, or only very slowly, attacked in acidic or neutral medium ${ }^{9-11}$. If $\left[\mathrm{OH}^{-}\right] \geq$ $0.1 \mathrm{~mol} \mathrm{dm}^{-3}$, permanganate is reduced in most case to manganate only, the reaction of which further proceeds at a much lower rate ${ }^{9,12,13}$. Nevertheless, since the process is very fast ${ }^{12-14}$, it cannot be decided, in general, whether permangate is reduced in one-electron steps or hypomanganate is first formed in a two-electron step followed by a fast reaction ${ }^{9}$.

$$
\mathrm{MnO}_{4}^{-}+\mathrm{MnO}_{4}{ }^{3-} \longrightarrow 2 \mathrm{MnO}_{4}{ }^{2-}
$$


Amino acids not only act as the building blocks in protein synthesis but also play a significant role in the metabolism. Histidine is a semiessential amino acid. It is found abundantly in hemoglobin; has been used in the treatment of rheumatoid arthritis, allergic diseases, ulcers and anemia. A deficiency can cause poor hearing. The importance of the amino acid, histidine lies in the fact that the body uses it to manufacture histamine, and histamine is responsible for a wide range of physiological processes. Apart from its sexual functions, histidine is involved in many other physiological processes. It is necessary for the production of red and white blood cells and supports the activity of suppressor $\mathrm{T}$ cells. Histidine is used as a supplement for sufferers of rheumatoid arthritis, since it has been shown that in these patients, histidine levels are low. Histidine is like many other amino acids, important for growth and general tissue repair.

Amino acids have been oxidized by variety of oxidizing agents ${ }^{15}$. Although much variety of organic ${ }^{16}$ and inorganic ${ }^{17}$ substrates are oxidized in aqueous alkaline medium, there are only a few reports ${ }^{18}$ on the oxidation of amino acids by aqueous alkaline permanganate. No work, however, has been reported on the oxidation of L-histidine by this oxidant in aqueous alkaline medium and so the present study deals with title reaction in order to understand the redox chemistry of permanganate in such media and to arrive a plausible mechanism.

\section{Experimental Materials}

All chemicals used were of reagent grade. Double distilled water was used throughout the work. Stock solution of L-histidine (Sisco-Chem. Ltd.) was prepared by dissolving the appropriate amount of sample in distilled water. The purity of the sample was checked by TLC and its m.p. was $283{ }^{\circ} \mathrm{C}$ (Literature $285^{\circ} \mathrm{C}$ ). The solution of potassium permanganate $(\mathrm{BDH})$ was prepared and standardized against oxalic acid ${ }^{19}$. Potassium manganate solution was prepared as described by Carrington and Symons ${ }^{20}$ as follows: an aqueous solution of potassium permanganate was heated to boiling $>100^{\circ} \mathrm{C}$ in $8.0 \mathrm{~mol} \mathrm{dm}^{-3} \mathrm{KOH}$ solution. Using the required amount of recrystalised sample, a stock solution of potassium manganate was then prepared in aqueous $\mathrm{KOH}$. The solution was standardized by measuring the absorbance on a Hitachi 150-20 spectrophotometer with a $1 \mathrm{~cm}$ Quartz cell at $608 \mathrm{~nm}$ $\left(\varepsilon=1530 \pm 20 \mathrm{dm}^{3} \mathrm{~mol}^{-1} \mathrm{~cm}^{-1}\right)$. All other reagents were of analytical grade and their solutions were prepared by dissolving requisite amounts of the samples in doubly distilled water. $\mathrm{NaOH}$ and $\mathrm{NaClO}_{4}$ were used to provide the required alkalinity and to maintain the constant ionic strength respectively.

\section{Kinetics measurements}

The oxidation of L-histidine by $\mathrm{KMnO}_{4}$ was followed under pseudo-first order conditions where [L-Hist] was excess over $\mathrm{MnO}_{4}{ }^{-}$at $30.0 \pm 0.1{ }^{\circ} \mathrm{C}$ unless stated otherwise. The reaction was initiated by mixing the required quantities of previously thermostatted solutions of $\mathrm{MnO}^{-}$and L-histidine, which also contained definite quantities of $\mathrm{NaOH}$ and $\mathrm{NaClO}_{4}$ to maintain the required alkalinity and ionic strength. The progress of the reaction was followed by measuring the absorbance of unreacted $\mathrm{MnO}_{4}{ }^{-}$ in the reaction mixture in a $1 \mathrm{~cm}$ quartz cell located in the thermostatted compartment of a Peltier Accessory (temperature control) attached Hitachi 150-20 spectrophotometer at $526 \mathrm{~nm}$; other constituents of the reaction mixture do not absorb significantly at this wavelength. Application of Beer's law to permanganate at $526 \mathrm{~nm}$ earlier had been verified, giving molar extinction coefficient ' $\varepsilon$ ' was found to be $2083 \pm 50 \mathrm{dm}^{3} \mathrm{~mol}^{-1} \mathrm{~cm}^{-1}$ (Literature $\varepsilon=2200 \mathrm{dm}^{3} \mathrm{~mol}^{-1} \mathrm{~cm}^{-1}$ ). The course of the reaction was followed by monitoring the decrease in the absorbance of $\mathrm{KMnO}_{4}$. The first order rate constants $\left(\mathrm{k}_{\mathrm{obs}}\right)$ were evaluated by plots of $\log \left(\mathrm{A}_{\mathrm{t}}-\mathrm{A}_{\infty}\right)$ versus time by fitting the data to the expression $A_{t}=A_{\infty}+\left(A_{0}-A_{\infty}\right) e^{-k_{\text {obs }} t}$, where $A_{t}, A_{O}$ and $A_{\infty}$ are the absorbances of $\mathrm{KMnO}_{4}$ of time $t, 0$, and $\infty$ respectively. In almost all cases the reaction was followed up to $75 \%$ completion of the reaction and the $\mathrm{k}_{\mathrm{obs}}$ values were reproducible within $\pm 5 \%$.

The effect of dissolved oxygen on the rate of reaction was studied by preparing the reaction mixture and following the reaction in an atmosphere of nitrogen. No significant difference between the results was observed. In view of the ubiquitous contamination of basic solutions by carbonate, the effect of carbonate on the reaction was also studied. Added carbonate had no effect on reaction rate. However, fresh solutions were used during the experiments. 


\section{Results}

Stoichiometry: Different sets of reaction mixtures containing L-histidine and an excess $\mathrm{MnO}_{4}{ }^{-}$with constant $\mathrm{OH}^{-}$and $\mathrm{NaClO}_{4}$ were kept for $6 \mathrm{~h}$ in closed vessels under $\mathrm{N}_{2}$ atmosphere. The remaining concentrations of $\mathrm{MnO}_{4}{ }^{-}$were assayed spectrophotometrically at $526 \mathrm{~nm}$. The results indicated 1:2 stoichiometry as given in equation (1).

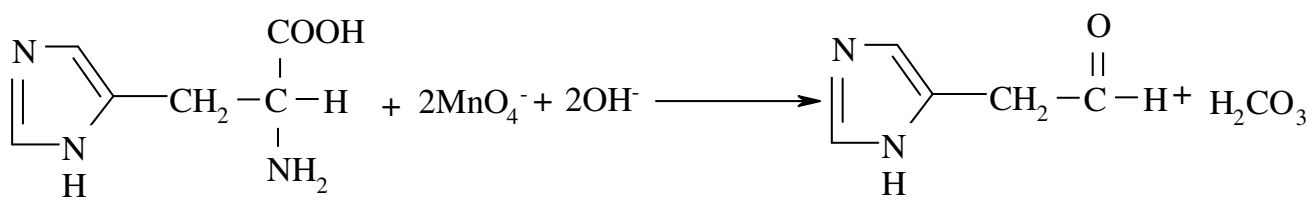

$$
+\mathrm{NH}_{3}+2 \mathrm{MnO}_{4}{ }^{2-}
$$

The main reaction products were identified as manganate by its visible spectra and 2-imidazole acetaldehyde ${ }^{21}$ by a spot test, ammonia ${ }^{19}$ by Nessler's reagent. The $\mathrm{CO}_{2}$ evolved is tested by bubbling nitrogen gas through a tube containing lime water ${ }^{22}$ after acidification. The quantitative estimation of aldehyde as its 2,4-DNP derivative was nearly $80 \%$. The aldehyde was also confirmed by its I.R. spectrum, which showed ${ }^{23}$ a band at $2919 \mathrm{~cm}^{-1}$ due to aldehydic C-H stretching and $1676 \mathrm{~cm}^{-1}$ due to carbonyl stretching. Tests for the corresponding acid were negative. It was also observed that the aldehyde does not undergo further oxidation under the present kinetic conditions.

Reaction order: The order with respect to [L-histidine] and [alkali] were found by $\log \mathrm{k}_{\mathrm{obs}}$ versus $\log$ concentration plots and were also confirmed by differential method by the plot log rate versus log concentration using the equation $\log$ rate $=\operatorname{logk}+\mathrm{n} \log \mathrm{c}$; these orders were obtained by varying the concentration of L-histidine and alkali in turn while keeping others constant.

The concentration of $\mathrm{MnO}_{4}{ }^{-}$was varied in the range, $4.0 \times 10^{-5}$ to $6.0 \times 10^{-4} \mathrm{~mol} \mathrm{dm}{ }^{-3}$ at fixed [Lhistidine], $\left[\mathrm{OH}^{-}\right]$and ionic strength. The non-variation in the pseudo-first order rate constants at various concentrations of $\mathrm{MnO}_{4}^{-}$indicates the order in $\left[\mathrm{MnO}_{4}{ }^{-}\right]$as unity (Table 1). This was also confirmed from the linearity of plots of log absorbance versus time $(r>0.9984, \mathrm{~S} \leq 0.025)$ up to $75 \%$ completion of the reaction. The substrate, [L-histidine] was varied in the range of $8.0 \times 10^{-4}$ to $8.0 \times 10^{-}$ ${ }^{3}$ mol dm${ }^{-3}$ at $30{ }^{\circ} \mathrm{C}$ keeping all other reactants concentrations constant. The $\mathrm{k}_{\mathrm{obs}}$ values were increase with increase in concentration of L-histidine and it was found to be less than unit order dependence on [L-histidine] (Table 1). The effect of [alkali] on the rate of reaction was studied at constant concentrations of L-histidine, $\mathrm{MnO}_{4}{ }^{-}$and ionic strength at $0.05 \mathrm{~mol} \mathrm{dm}^{-3}$. The rate constants increased with increase in [alkali] and the order was also found to be less than unity (Table 1).

Effect of ionic strength and solvent polarity: The effect of ionic strength was studied by varying the $\mathrm{NaClO}_{4}$ concentration from $5.0 \times 10^{-3}$ to $5.0 \times 10^{-2} \mathrm{~mol} \mathrm{dm}^{-3}$ at constant concentration of permanganate, L-Histdine and alkali. It was found that the rate of reaction increased with increasing the concentration of $\mathrm{NaClO}_{4}$; the plot of $\operatorname{logk}_{\text {obs }}$ versus $\mathrm{I}^{1 / 2}$ is linear with a positive slope (Fig. 1).

The relative permitivity effect was evaluated by variation of the $t$-butanol-water content while keeping all other conditions constant. Attempts to measure the relative permittivities failed; however, they were computed from the values of pure liquids ${ }^{24,25}$. The inertness of the solvent with respect to the oxidant was checked under the experimental conditions. There was no reaction of the solvent with the oxidant. The rate constant $\mathrm{k}_{\mathrm{obs}}$ decrease with decreasing dielectric constant of the medium.

Effect of Initially added products: The effect of addition of products of the reaction, such as manganate, ammonia and aldehyde on rate of reaction were investigated. Addition of these products did not affect the reaction rate significantly. 
Test for free radicals: To test the intervention of free radicals, the reaction mixture was mixed with acrylonitrile monomer and kept for 24 hours under nitrogen atmosphere. On dilution with methanol, white precipitate of polymer was formed, indicating the intervention of free radicals during the reaction. The blank experiment of either $\mathrm{KMnO}_{4}$ or L-histidine in with acrylonitrile alone did not induce polymerization under the same condition as those induce with reaction mixture. Initially added acrylonitrile decreases the rate indicating the free radical intervention, which is the case as observed in earlier work ${ }^{26}$.

Effect of Temperature: The rate of reaction was measured at different temperatures under varying Lhistidine and alkali concentrations. The rate of reaction increased with the increase of temperature. The rate constants, $\mathrm{k}$ of slow step of scheme 1 were obtained from intercepts of the plots of $1 / \mathrm{k}_{\text {obs }}$ versus $1 /$ [L-histidine] $(\mathrm{r}>0.9978, \mathrm{~S} \leq 0.0162)$ as $3.43 \times 10^{-3}, 4.03 \times 10^{-3}, 4.75 \times 10^{-3} \mathrm{~s}^{-1}$ at $30,35,40,45^{0} \mathrm{C}$ respectively. The activation parameters corresponding to these constants were evaluated from the plot of $\log \mathrm{k}$ versus $1 / \mathrm{T}(\mathrm{r}>0.9989, \mathrm{~S} \leq 0.0135)$ and are tabulated in Table 2.

\section{Discussion}

Potassium permanganate is widely used as an oxidizing agent in synthetic as well as in analytical chemistry and also as a disinfectant. The reactions are governed by $\mathrm{pH}$ of the medium. Among six oxidation states of manganese from $2+$ to $7+$, permanganate, $\mathrm{Mn}(\mathrm{VII})$, is the most potent oxidation state in acid as well as in alkaline media.

The reaction between permanganate and L-histidine in alkaline medium has a stoichiometry of 1:2 reductant to oxidant with first order dependence on $\left[\mathrm{MnO}_{4}^{-}\right]$, apparent less than unit order in $\left[\mathrm{OH}^{-}\right]$ and [L-histidine]. The active species of permanganate in aqueous alkaline medium may be deduced from the dependence of the rate on $\left[\mathrm{OH}^{-}\right]$in the reaction medium. The apparent order of less than unity in $\mathrm{OH}^{-}$may be indication of formation of alkaline permanganate ion in prior equilibrium step ${ }^{27}$. The formation of $\mathrm{MnO}_{4} \mathrm{OH}^{2-}$ species in alkaline medium further supported by the Michaelis-Menten plot, which is linear with a positive intercept (Fig. 2). It is also known that permanganate ion in alkaline medium exist as $\mathrm{MnO}_{4} \mathrm{OH}^{2-}$. Thus, it reacts with L-histidine and leads to the formation a complex (C) in a prior equilibrium step. Then this complex (C) decomposes in a slow step to form a free radical species derived from L-histidine. This free radical reacts with another molecule of $\left[\mathrm{MnO}_{4} \mathrm{OH}\right]^{2-}$ species in a fast step to yield the products. All the results indicate a mechanism as given in Scheme $\mathbf{1}$.

$$
\mathrm{MnO}_{4}^{-}+\mathrm{OH}^{-} \rightleftharpoons \mathrm{K}_{1} \rightleftharpoons\left[\mathrm{MnO}_{4} \mathrm{OH}\right]^{-}
$$
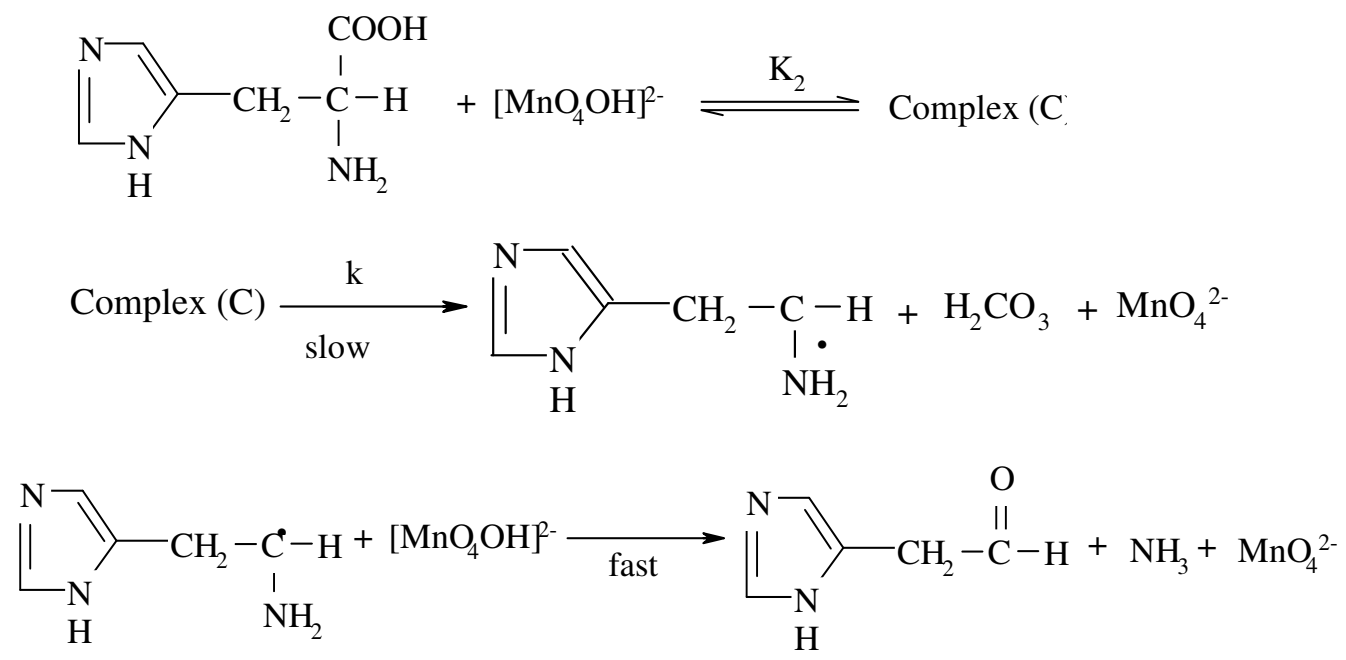
The probable structure of complex $(\mathrm{C})$ is<smiles>[3H]C(=O)[C@@H](N)Cc1cnc[nH]1</smiles>

The spectral evidence for the complex (C) formation between oxidant and substrate was obtained from UV-VIS Spectra of the oxidant and mixtures of substrate and oxidant. Analogous effects upon complex (C) formation between a substrate and an oxidant have been observed earlier [28]. The formation of the complex (C) is also proved kinetically by the non-zero intercept of the plot of $1 / \mathrm{k}_{\mathrm{obs}}$ versus $1 /$ [L-Hist] $(r>0.9998, \mathrm{~S} \leq 0.0152)$ (Fig. 3). Since scheme 1 is in accordance with the generally well-accepted principle of non-complementary oxidations taking place in sequence of one-electron steps, the reaction between the substrate and oxidant would afford a radical intermediate. A free radical scavenging experiment revealed such a possibility. This type of radical intermediate has also been observed in earlier work ${ }^{29}$.

Scheme 1 leads to the rate law equation (1),

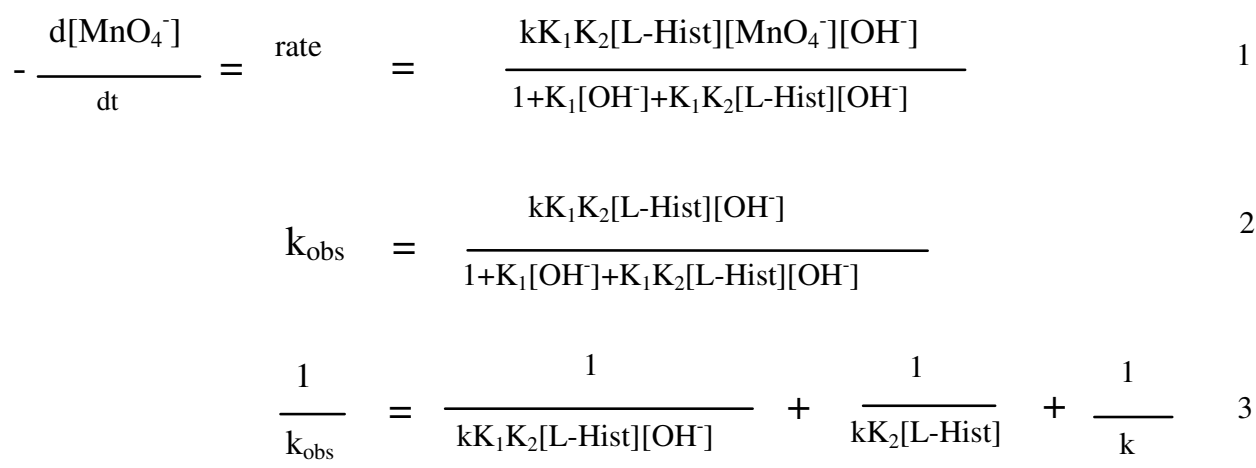

According to equation (3), the plots of $1 / \mathrm{k}_{\mathrm{obs}}$ versus $1 /\left[\mathrm{OH}^{-}\right](\mathrm{r}>0.9989, \mathrm{~S} \leq 0.0121)$ and $1 / \mathrm{k}_{\mathrm{obs}}$ versus 1/[L-Hist] ( $>0.9998, \mathrm{~S} \leq 0.0152)$ should be linear as shown in figure 2 and 3 . From the slopes and intercepts, the values of $\mathrm{k}, \mathrm{K}_{1}$ and $\mathrm{K}_{2}$ could be derived as $3.43 \times 10^{-3} \pm 0.06 \mathrm{~s}^{-1}, 15.72 \pm 0.25 \mathrm{dm}^{3} \mathrm{~mol}^{-1}$ and $29.54 \pm 0.24 \times 10^{2} \mathrm{dm}^{3} \mathrm{~mol}^{-1}$ respectively. Using these constants, the rate constants were calculated over different experimental conditions and there is a reasonable agreement between the calculated and experimental values (Table 1), which verifies the proposed mechanism.

The small effect of ionic strength on the reaction is presumably due to the fact that the reaction takes place between a neutral and charged species (Scheme 1). A plot of log $\mathrm{k}_{\mathrm{obs}}$, against $\mathrm{I}^{1 / 2}$ according to Debye-Huckel equation was linear with a positive slope. However, the present measurements, of necessity, lie far outside the Debye-Huckel region, covering a range over which the activity coefficient of many electrolytes are known to be fairly dependent on ionic strength ${ }^{30}$. The ionic strength dependence is qualitatively as expected when considering the charges involved ${ }^{31}$. The effect of solvent on reaction rate was studied ${ }^{32}$ by varying the t-butyl alcohol-water content in the reaction mixture with all other conditions being constant. Increasing the content of t-butyl alcohol in the reaction medium 
leads to an increase in the rate of reaction. The plot of $\log \mathrm{k}_{\mathrm{obs}}$ versus $1 / \varepsilon_{\mathrm{T}}(\mathrm{r}>0.9998, \mathrm{~S}<0.0112)$ is expected to be linear with a negative slope for a reaction between a negative ion and neutral molecule, where as positive slope results for a positive ion and neutral molecule. In the present study, a plot of $\log \mathrm{k}_{\mathrm{obs}}$ vs. $1 / \varepsilon_{\mathrm{T}}(\mathrm{r}>0.9998, \mathrm{~S}<0.0112)$ is linear with negative slope (Fig. 2) which supports the involvement of negative ions as given in Scheme 1.

Table 1. Effect of variation of $\left[\mathrm{KMnO}_{4}\right]$, [L-Hist $]$ and $\left[\mathrm{OH}^{-}\right]$on oxidation of L-histidine by alkaline $\mathrm{KMnO}_{4}$ at $30{ }^{\circ} \mathrm{C}, \mathrm{I}=0.05 \mathrm{~mol} \mathrm{dm}{ }^{-3}$.

\begin{tabular}{|c|c|c|c|c|}
\hline \multirow{2}{*}{$\begin{array}{r}10^{4} \mathrm{x}\left[\mathrm{KMnO}_{4}^{-}\right] \\
\mathrm{mol} \mathrm{dm}^{-3}\end{array}$} & \multirow{2}{*}{$\begin{array}{r}10^{3} \mathrm{x} \text { [L-Hist] } \\
\mathrm{mol} \mathrm{dm}^{-3}\end{array}$} & \multirow{2}{*}{$\begin{array}{c}10^{3} \times\left[\mathrm{OH}^{-}\right] \\
\mathrm{mol} \mathrm{dm}\end{array}$} & \multicolumn{2}{|c|}{$10^{3} \times k_{o b s} \mathrm{~s}^{-1}$} \\
\hline & & & Found & Calcd.* \\
\hline 0.4 & 2.0 & 5.0 & 1.04 & 1.03 \\
\hline 0.6 & 2.0 & 5.0 & 1.03 & 1.03 \\
\hline 1.0 & 2.0 & 5.0 & 1.05 & 1.03 \\
\hline 2.0 & 2.0 & 5.0 & 1.03 & 1.03 \\
\hline 4.0 & 2.0 & 5.0 & 1.02 & 1.03 \\
\hline 6.0 & 2.0 & 5.0 & 1.03 & 1.03 \\
\hline 2.0 & 0.8 & 5.0 & 0.50 & 0.50 \\
\hline 2.0 & 1.0 & 5.0 & 0.61 & 0.61 \\
\hline 2.0 & 2.0 & 5.0 & 1.05 & 1.03 \\
\hline 2.0 & 4.0 & 5.0 & 1.59 & 1.58 \\
\hline 2.0 & 6.0 & 5.0 & 1.88 & 1.93 \\
\hline 2.0 & 8.0 & 5.0 & 2.18 & 2.17 \\
\hline 2.0 & 2.0 & 2.0 & 0.52 & 0.52 \\
\hline 2.0 & 2.0 & 4.0 & 0.90 & 0.89 \\
\hline 2.0 & 2.0 & 5.0 & 1.05 & 1.03 \\
\hline 2.0 & 2.0 & 8.0 & 1.35 & 1.36 \\
\hline 2.0 & 2.0 & 10.0 & 1.53 & 1.53 \\
\hline 2.0 & 2.0 & 20.0 & 2.27 & 2.01 \\
\hline
\end{tabular}

The activation parameters of the reaction are calculated by a plot of logk versus $1 / \mathrm{T}$ as given in Table 2. The experimental values of $\Delta \mathrm{H}^{\#}$ and $\Delta \mathrm{S}^{\#}$ were both favorable for electron transfer processes. The high negative value of $\Delta S^{\#}$ indicates that interaction of reacting ions of similar charges to form an activated complex and is more ordered than the reactants due to loss of degree of freedom. This also supports by a small value of frequency factor ${ }^{33}$.

The hydroxyl ion concentration (as in Table 1) was verified at four different temperatures and the $\mathrm{K}_{1}$ values were determined as $15.72 \mathrm{dm}^{3} \mathrm{~mol}^{-1}, 17.77 \mathrm{dm}^{3} \mathrm{~mol}^{-1}, 19.77 \mathrm{dm}^{3} \mathrm{~mol}^{-1}, 21.99 \mathrm{dm}^{3} \mathrm{~mol}^{-1}$ at 30, 35, 40 and $45{ }^{\circ} \mathrm{C}$ respectively (Fig. 2). Similarly L-histidine concentration as in Table 1 was varied at four different temperatures and $\mathrm{K}_{2}$ values were determined at each temperature (Fig. 3). The values of $\mathrm{K}_{2}$ were obtained as $29.54 \times 10^{2} \mathrm{dm}^{3} \mathrm{~mol}^{-1}, 26.69 \times 10^{2} \mathrm{dm}^{3} \mathrm{~mol}^{-1}$, and $23.64 \times 10^{2} \mathrm{dm}^{3} \mathrm{~mol}^{-1}$, $21.12 \times 10^{2} \mathrm{dm}^{3} \mathrm{~mol}^{-1}$ at $30,35,40$ and $45{ }^{0} \mathrm{C}$ respectively. A van't Hoff's plot was made for the variation of $K_{1}$ with temperature (i.e. $\log \mathrm{K}_{1}$ versus $1 / \mathrm{T}$ ). Values of the enthalpy change of the first equilibrium step $\left(\mathrm{K}_{1}\right)$ of the reaction $(\Delta \mathrm{H})$, entropy of the reaction $(\Delta \mathrm{S})$ and free energy of reaction $(\Delta \mathrm{G})$ were calculated (Table 2 ) as $17.86 \pm 0.25 \mathrm{~kJ} / \mathrm{mol}, 81.87 \pm 2.0 \mathrm{~J} \mathrm{~K}^{-1} \mathrm{~mol}^{-1}$ and $-6.706 \mathrm{~kJ} / \mathrm{mol}$ respectively. Similarly, thermodynamic parameters for second step $\left(\mathrm{K}_{2}\right)$ are calculated as $-18 \pm 2 \mathrm{~kJ} /$ mol, $7 \pm 1 \mathrm{~J} / \mathrm{mol}, \quad-20 \pm 2 \mathrm{~kJ} / \mathrm{mol}$ for change in enthalpy $(\Delta \mathrm{H})$, change in entropy of the reaction $(\Delta \mathrm{S})$ and change in free energy of the reaction $(\Delta \mathrm{G})$ respectively (Fig. 4). The proposed mechanism is also 
supported by the above thermodynamic parameters. The latter values with those obtained for slow step of the reaction shows that these values mainly refer to the rate limiting step, supporting the fact that the reaction before the rate determining step are fairly slow and involves high activation energy ${ }^{34}$.

Figure 1. Plot of $\log \mathrm{k}_{\mathrm{obs}}$ versus $\log 1 / \mathrm{D}$ and $\log \mathrm{k}_{\mathrm{obs}}$ versus $\mathrm{I}^{1 / 2}$.

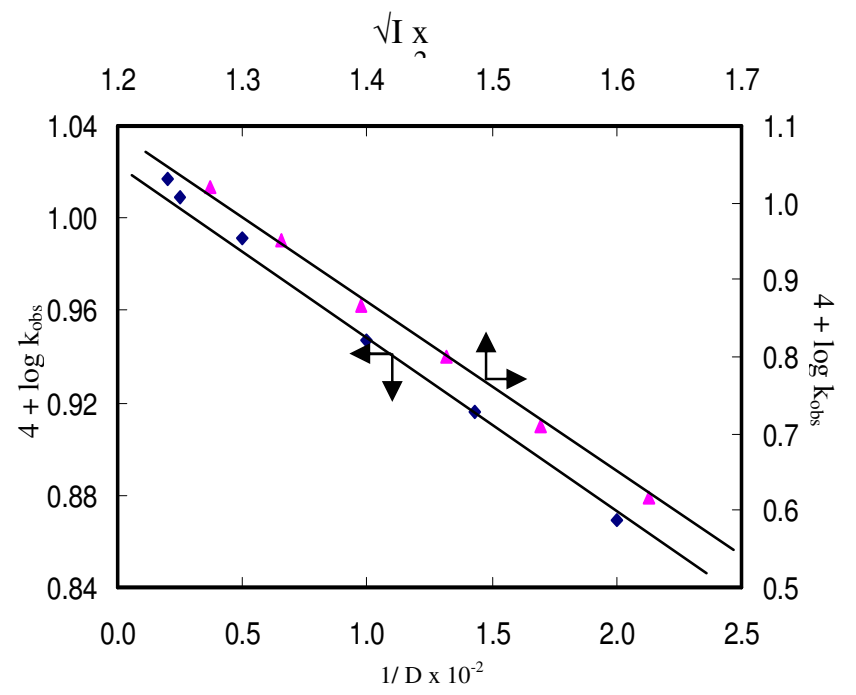

Table 2. Activation parameters for the oxidation of L-histidine by alkaline permanganate $\left[\mathrm{KMnO}_{4}\right]=$ $2.0 \times 10^{-4} \mathrm{~mol} \mathrm{dm}^{-3},[$ L-Hist $]=2.0 \times 10^{-3} \mathrm{~mol} \mathrm{dm}^{-3},\left[\mathrm{OH}^{-}\right]=0.005 \mathrm{~mol} \mathrm{dm}^{-3}$ and $\mathrm{I}=0.05 \mathrm{~mol} \mathrm{dm}^{-3}$.

\begin{tabular}{cc}
\hline Activation Parameters & Values \\
\hline$E a\left(\mathrm{~kJ} \mathrm{~mol}^{-1}\right)$ & $29.0 \pm 1.4$ \\
$\Delta H^{\#}\left(\mathrm{~kJ} \mathrm{~mol}^{-1}\right)$ & $26.5 \pm 1.3$ \\
$\Delta S^{\#}\left(\mathrm{~J} \mathrm{~K}^{-1} \mathrm{~mol}^{-1}\right)$ & $-49.7 \pm 2.2$ \\
$\Delta G^{\#}\left(\mathrm{~kJ} \mathrm{~mol}^{-1}\right)$ & $41.5 \pm 1.5$ \\
$\operatorname{Log~A}$ & 5.01 \\
\hline
\end{tabular}

Variation in the rate within a reaction series may be caused by change in the enthalpy and or entropy of activation. Changes in the rate are caused by changes in both $\Delta H^{\#}$ and $\Delta S^{\#}$, but these quantities vary extensively in a parallel fashion. A plot of $\Delta H^{\#}$ versus $\Delta S^{\#}$ is linear according to equation, $\Delta H^{\#}=\beta \Delta S^{\#}$ + constant, $\beta$ is called the isokinetic temperature; it has been asserted that apparently linear correlation of $\Delta H^{\#}$ with $\Delta S^{\#}$ are some times misleading and the evaluation of $\beta$ by means of the above equation lacks statistical validity ${ }^{35}$. Exner ${ }^{36}$ advocates an alternative method for the treatment of experimental data. If the rates of several reactions in a series have been measured at two temperatures and $\log \mathrm{k}_{2}$ (at $\mathrm{T}_{2}$ ) is linearly related to $\log \mathrm{k}_{1}\left(\right.$ at $\mathrm{T}_{1}$ ) (Fig 5.) i.e. $\log \mathrm{k}_{2}=\mathrm{a}+\mathrm{b} \log \mathrm{k}_{1}$, he proposes that $\beta$ can be evaluated from the equation, 
Figure 2. Rate law plots $\left(1 / \mathrm{k}_{\mathrm{obs}}\right.$ versus $1 /\left[\mathrm{OH}^{-}\right]$)of oxidation of L-Histidine by potassium permanganate in aqueous alkaline medium at different temperatures. (conditions as in Table 1)

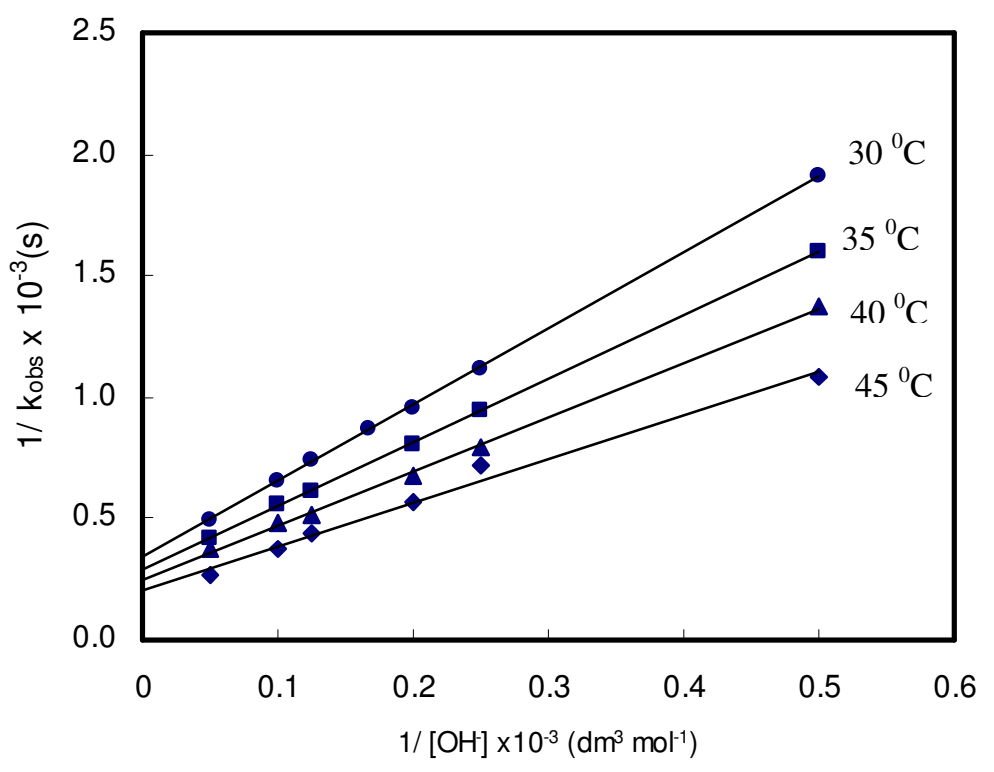

Figure 3. Rate law plots $\left(1 / \mathrm{k}_{\mathrm{obs}}\right.$ versus $1 /$ [L-histidine] )of oxidation of L-Histidine by potassium permanganate in aqueous alkaline medium at different temperatures. (conditions as in Table 1)

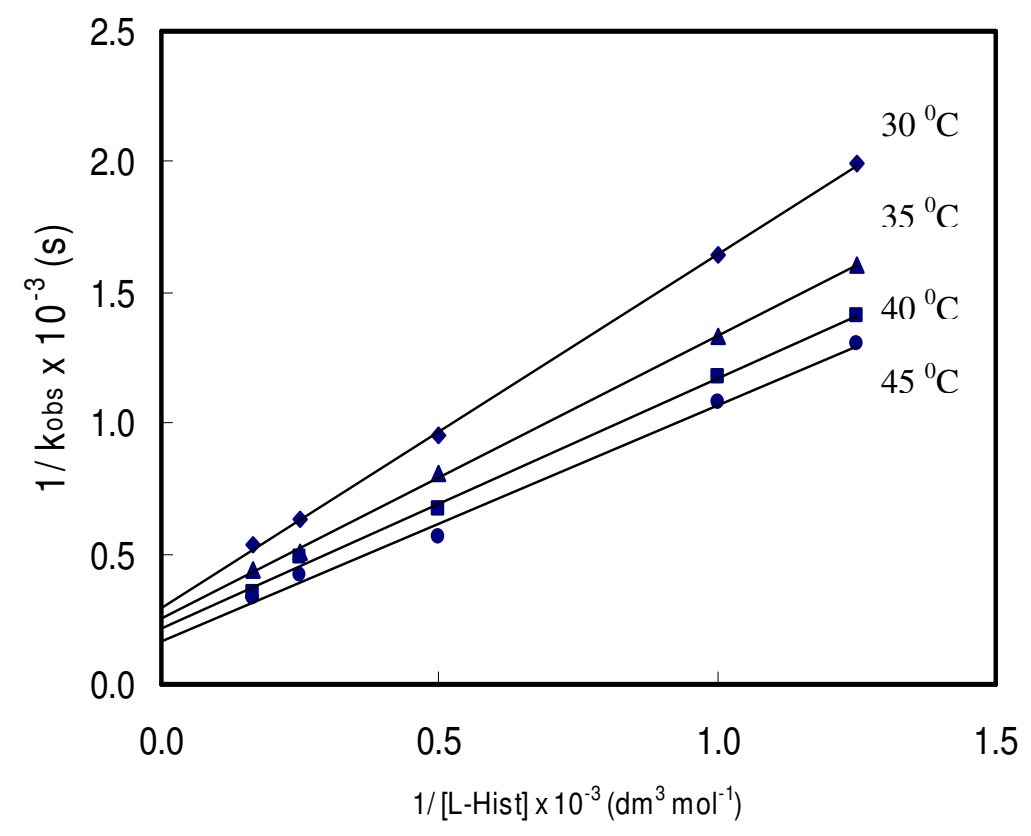


Table 3. Activation parameters for oxidation of some amino acids by alkaline $\mathrm{KMnO}_{4}$.

\begin{tabular}{|c|c|c|c|c|c|c|}
\hline Amino acid & $\begin{array}{c}\mathrm{k}_{1} \times 10^{2} \\
\mathrm{~s}^{-1} \\
\text { at } 298 \mathrm{~K}\end{array}$ & $\begin{array}{c}\mathrm{k}_{2} \times 10^{2} \\
\mathrm{~s}^{-1} \\
\text { at } 303 \mathrm{~K}\end{array}$ & $\begin{array}{c}\Delta S^{\#} \\
\mathrm{~J} \mathrm{~K}^{-1} \mathrm{~mol}^{-1}\end{array}$ & $\begin{array}{c}\Delta H^{\#} \\
\mathrm{k} \mathrm{J} \mathrm{mol}^{-1}\end{array}$ & $\begin{array}{c}\Delta G^{\#} \\
\mathrm{k} \mathrm{J} \mathrm{mol}^{-1}\end{array}$ & References \\
\hline Rac-Serine & 10.00 & 28.00 & $-28 \pm 2.4$ & $49 \pm 1$ & $58 \pm 3$ & 38 \\
\hline $\begin{array}{c}\mathrm{L}(+) \text { Aspartic } \\
\text { acid }\end{array}$ & 2.22 & 8.84 & $-83 \pm 10$ & $40 \pm 3$ & $64.7 \pm 3$ & 39 \\
\hline Glutamic acid & 4.00 & 6.13 & $-86 \pm 4$ & $45 \pm 2.5$ & $70.6 \pm 1$ & 40 \\
\hline \multicolumn{7}{|l|}{ L-histidine } \\
\hline & 0.27 & 0.34 & $-49.7 \pm 2.2$ & $26.5 \pm 1.3$ & $41.5 \pm 2$ & $\begin{array}{c}\text { Present } \\
\text { work }\end{array}$ \\
\hline
\end{tabular}

$$
\beta=\mathrm{T}_{1} \mathrm{~T}_{2}(\mathrm{~b}-1) /\left(\mathrm{T}_{2} \mathrm{~b}-\mathrm{T}_{1}\right)
$$

We have calculated the isokinetic temperature, $\beta$ as $277.7 \mathrm{~K}$ by plotting $\log \mathrm{k}_{2}$ at $303 \mathrm{~K}$ versus $\log \mathrm{k}_{1}$ at $298 \mathrm{~K}$ (Fig. 5) $(\mathrm{r} \geq 0.979 \& \mathrm{~s} \leq 0.0051)$ for a series of $\alpha$-amino acids like rac-serine, L-(+) aspartic acid, L-glutamic acid and present work. The value of $\beta(277.7 \mathrm{~K})$ is smaller than the experimental temperature $(303 \mathrm{~K})$. This indicates that the rate is governed by the enthalpy of activation ${ }^{37}$. The linearity and the slope of the plot obtained may confirm that the kinetics of these reactions follow similar mechanisms, as previously suggested (free radical intervention). However, the higher value of $\mathrm{S}^{\#}$ of L (+)-aspartic acid and L-glutamic acid is due to the stabilization of carbocation by successive $\mathrm{CH}_{3}$ group(s) which is unlike in L-histidine.

Figure 4. Effect of temperature on $\mathrm{KMnO}_{4}$ oxidation of L-histidine in aqueous alkaline medium for mechanism of step 1 and 2 as per Scheme 1 .

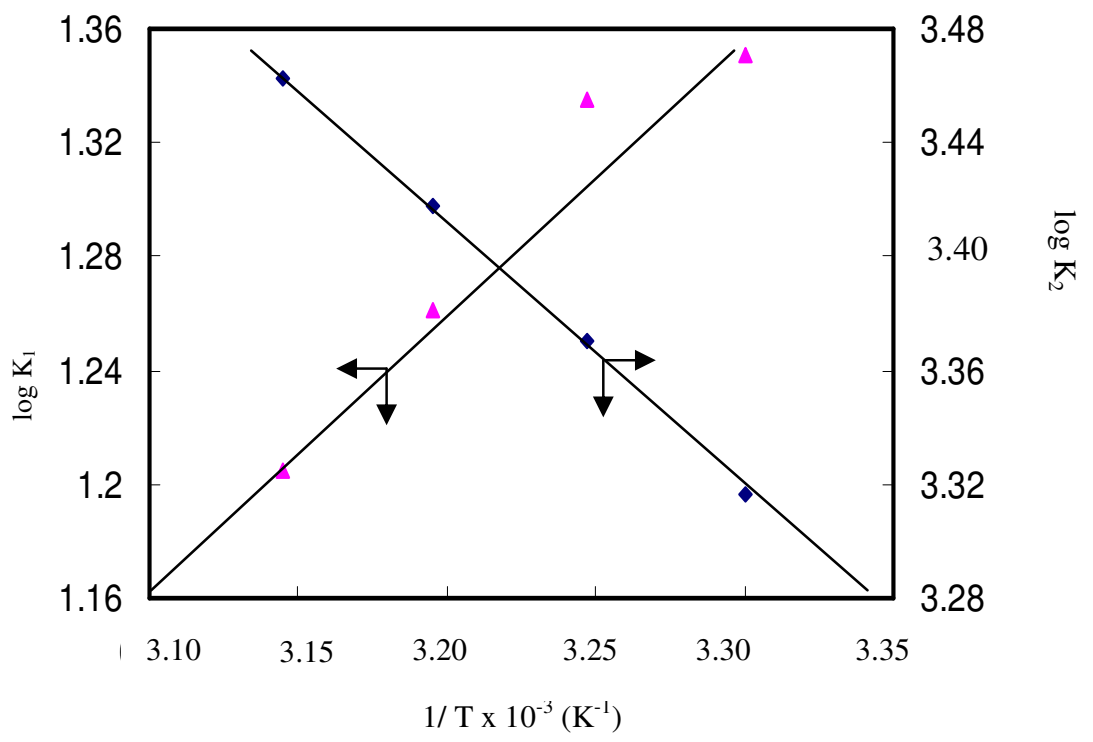


Figure 5. Plot of $\log \mathrm{k}_{2}$ at $303 \mathrm{~K} v s . \log \mathrm{k}_{1}$ at $298 \mathrm{~K}$ for a series of amino acids (Table 3) 1. Rac-Serine, 2. L(+)-Aspartic acid, 3. L-Glutamic acid and 4. L-histidine.

\section{Acknowledgement}

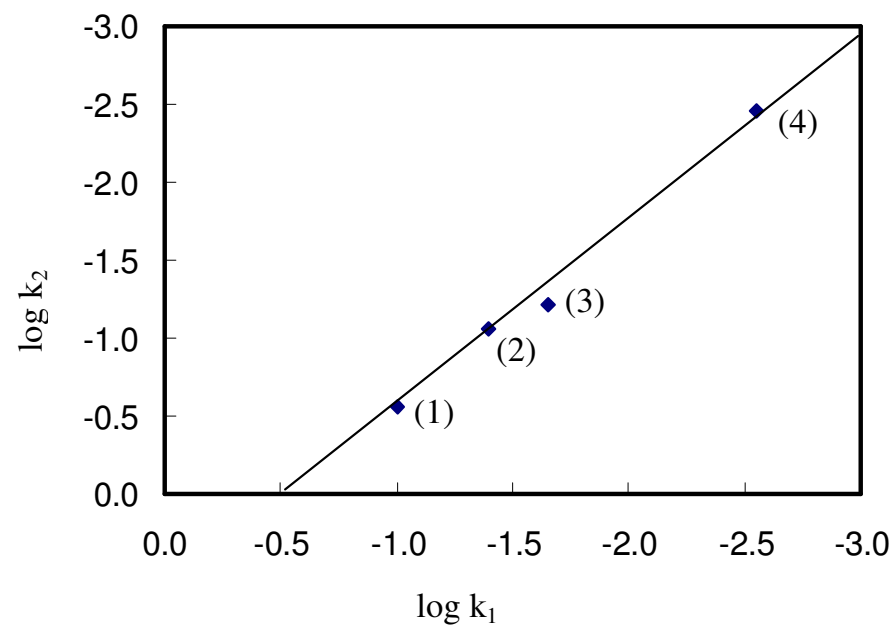

One of the authors S. M. Tuwar thanks the UGC, Regional Office Bangalore, for providing financial assistance

\section{References}

1. Stewart R, in Wiberg, K.B. (ed.), Oxidation in Organic Chemistry, Part A, Academic Press, New York, Ch.1 1965.

2. Freeman F, Rev. React. Species Chem. React., 1976, 1, 179.

3. Lee D G, The Oxidation of Organic Compounds by Permanganate Ion and Hexavalent Chromium, Open Court, La Salle, IL,1980.

4. Lee D G, Tranhanovsky, W.S. (ed.), Oxidation in Organic Chemistry, Part D, Academic Press, New York, 1982, p.147.

5. Simandi L I, Patai S and Rappoport Z, (eds.), The Chemistry of the functional groups, Suppl. C, Chichester, 1983, chapter.13.

6. Lee D G, Lee E J and Brown, K.C. Phase transfer Catalysis and Applications, Acs Symposium Series No.326, American Chemical Society, Washington, DC, 1987, p. 2.

7. Fatiadi A J, Synthesis, 1987, 85.

8. Wiberg K B, Deutsch C J and Rocek J, J. Am. Chem. Soc., 1973,5, 3034.

9. Drummond Y A and Waters W A, J.Chem. Soc., 1935, 435.

10. Ladburry J C and Cullis C F, Chem.,Rev, 1958, 58, 403.

11. Waters W A, Quart. Rev. 1958, 12, 272.

12. Pode J S F and Waters W A, J.Chem.Soc., 1956, 717.

13. Stewart R., Oxidation in organic Chemistry, Part A, K.B. Wiberg, Ed., Academic Press, New York, 1965.

14. Carrington A and Symons M C R, Chem. Rev., 1963, 63, 443.

15. Mahadevappa D S, Rangappa K S, Gowda N M M and Timme Gowda B, Int. J.Chem.Kinet., 1982,14,1183; Timme Gowda B and Sherigara B S, Oxid. Commun., 1986, 9,165; Laloo D and Mahanti M K, Polish J.Chemistry, 1986, 60, 589. 
16. Szammer J, Jacky M and Germasimov O V, Int.J.Chem.Kinet., 1992, 24,145; Jaky M, Kozhevnikov I V and Hoft E, Int.J.Chem.Kinet., 1992, 24, 1055.

17. Simandi P I, Jaky M and Schelly Z A, J. Am. Chem. Soc., 1985,107, 4220;

18. Bal Reddy K, Sethuram B and Navaneeth Rao, Indian J. Chem., 1981, 20A,395; Hogle M P and Pawar P K, Acta. Ciene. Indica. Chem., 1986, 12A, 228.; Laloo D and Mahanti M K, Polish J.Chem., 1986, 60, 589.

19. Jeffery G H, Bassett J, Mendham J and Denney R C, Vogel's Text Book of Quantitative Chemical Analysis, 5th Ed., ELBS Longman, Essex, UK, 1996, p. 371.

20. Carrington A and Symons M C R, J. Chem. Soc., 1956, 3373.

21. Feigl F, Spot Tests in Organic Analysis, Elsevier Scientific Publishing, New York, 1975, p.195.

22. Dass A K and Dass M, J. Chem. Soc. Dalton Trans., 1994, 589.

23. Ballamy L J, The IR Spectra of Complex Molecules, Methuen and Co, London, 2nd Ed., 1958, p. 425.

24. Hugar G H and Nandibeboor S T, Transition Met. Chemistry., 1994, 19, 215.

25. Nadibewoor S T, Hiremth G A and Timmanagoudar P L, Transition Met. Chemistry, 2000, $\mathbf{2 5}, 394$.

26. Kolthoff I M, Meehan E J and Carr E M, J. Am. Chem. Soc., 1953, 75, 1439; Bhattacharya S and Benerjee P, Bull. Chem. Soc. Japan, 1996, 69, 3475.

27. Panari R G, Chougale R B and Nandibewoor S T, J. phys. Org. Chem., 1998, 11, 448.

28. Devi J, Kotahari S and Banerjee K K, Indian J. Chem., 1995, 34A, 116.

29. Jaky M, Szeverenyi M and Simandi L I, Inorg. Chem. Acta., 1991, 33, 186; Lott K A K and Symons M C R, Discuss Farday Soc., 1960, 29, 205.

30. Wiberg K B and Stewart R, J. Am. Chem. Soc., 1956, 78, 1214.

31. Laidler K, Chemical Kinetics, McGraw-Hill, New York, 1965.

32. Basolo F, Pearson, R.G., Mechanisms of Inorganic Reactions, Wiley, New York, London, Sydney, 2nd Ed.,1967, p.34.

33. Weissberger A (Ed), Investigation of Rates and Mechanism of Reactions In Techniques of Chemistry, Lewis E S, Wiley, Interscience Publication, New York, 1974, p .421.

34. Rangappa K S, Raghavendra M P, Mahadevappa D S and Channagouda D, J. Org. Chem., 1998, 63, 531.

35. Lewis E S, Investigation of rates and Mechanism of reactions, Wiley, NewYork., 3rd Ed. 1974, p. 415.

36. Exner O, Coll. Czech, Chem. Commun., 1964, 29, 1094; Exner, O. Coll Czech. Chem. Commum., 1972, 37, 1425.

37. Leffler J E, J. Org. Chem., 1955, 20, 1202.

38. Halligudi N N, Desai S M, Mavalangi A K and Nandibewoor S T, Mon. Fur. Chem., 2000, 131, 321.

39. Chougale R B, Panari R G and Nandibewoor S T, Oxidn. Commun., 1999, 22, 298.

40. Chougale R B, Panari R G and Nandibewoor S T, Oxidn. Commun., 1998, 21, 565. 


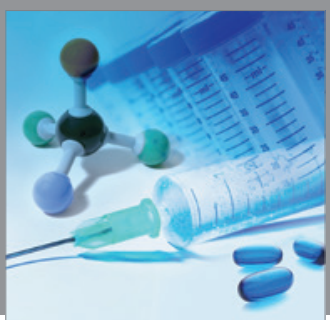

International Journal of

Medicinal Chemistry

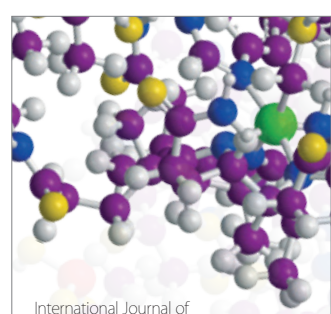

Carbohydrate Chemistry

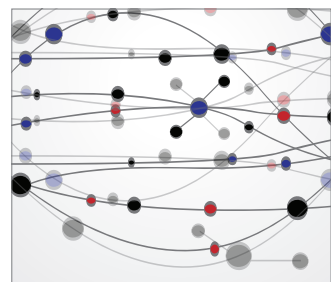

The Scientific World Journal
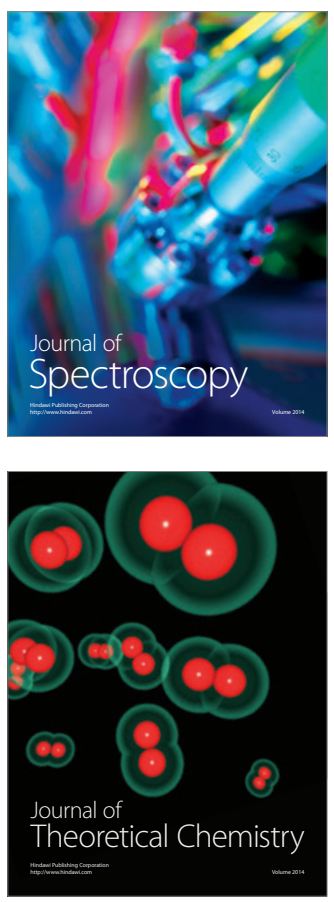
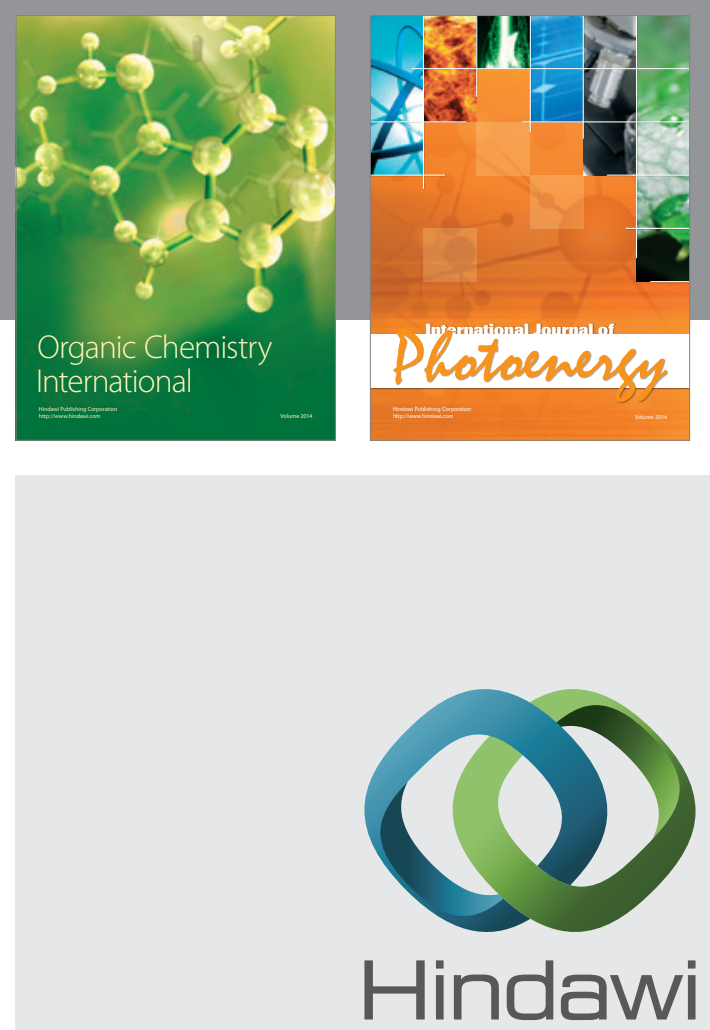

Submit your manuscripts at

http://www.hindawi.com
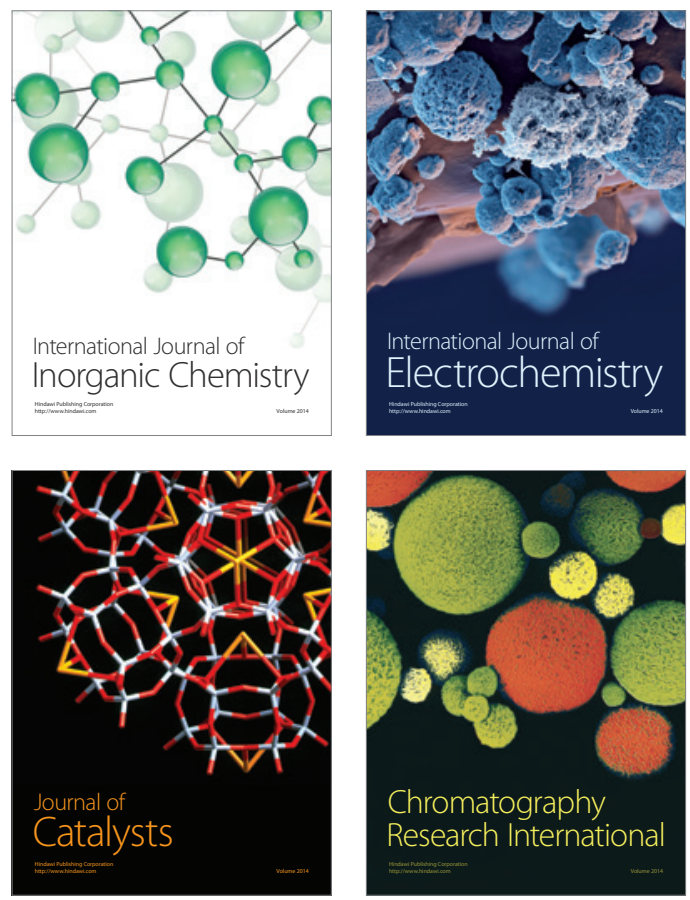
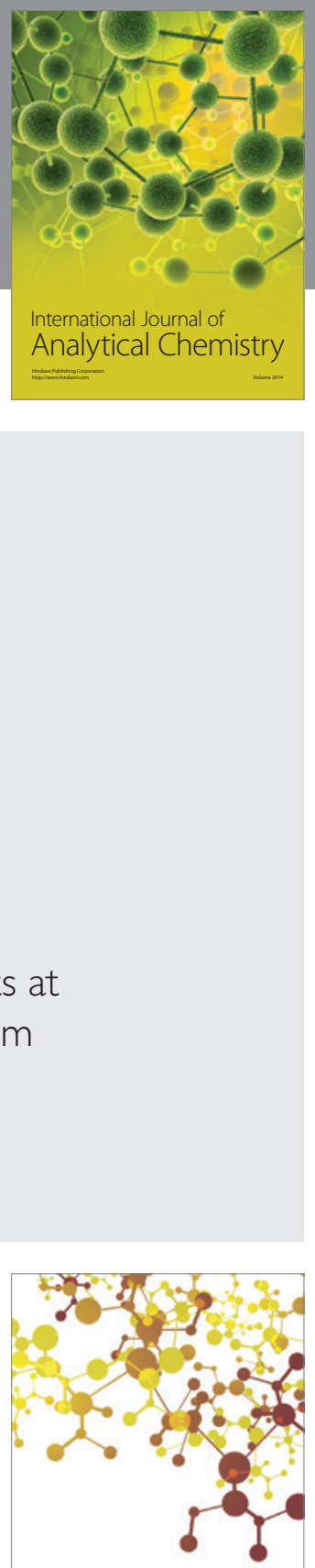

Journal of

Applied Chemistry
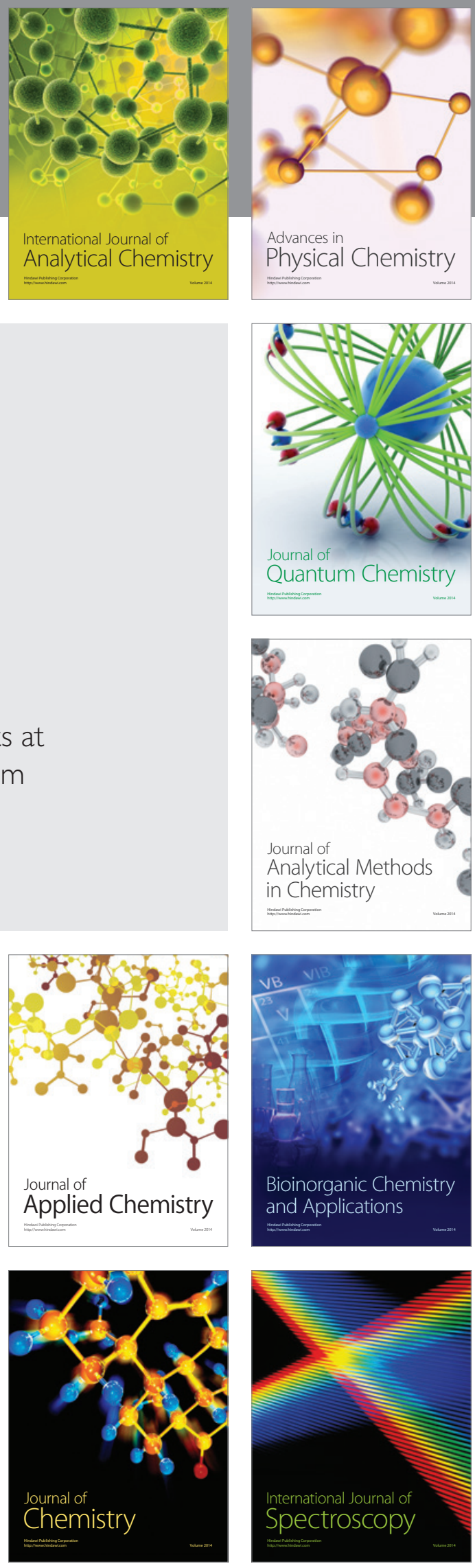